\title{
Effects of Temporally Heterogeneous Hydrological Experiences On Subsequent Performance And Plasticity of Exotics And Natives From Different Habitats
}

Shu Wang ( $\nabla$ Inbx625@163.com )

Guizhou University https://orcid.org/0000-0002-5353-6744

Ragan M. Callaway

The University of Montana

\section{Research Article}

Keywords: Drought stress, Early experience, Habitat range, Meta-plasticity, Temporal heterogeneity, Exotic species

Posted Date: July 6th, 2021

DOl: https://doi.org/10.21203/rs.3.rs-634210/v1

License: (c) (1) This work is licensed under a Creative Commons Attribution 4.0 International License. Read Full License 


\section{Abstract}

Aims Temporally heterogeneous environments have crucial influences on plant survival and growth, leading to greater variations in plasticity, but direct experimental evidence is rare. Our objective was to investigate how early experience with temporally heterogeneous water conditions may affect the subsequent performance and plasticity of plants in response to water availability.

Methods We subjected eight plant species from xeric, mesic or hydric habitats, four exotic and four native to North America, to initial exposure to either an alternating drought and inundation treatment ( $E_{\text {het }}$ heterogeneous experience) or a consistently moderate water supply ( $E_{h o m}$, homogeneous experience), and to a second round of drought, moderate watering or inundation treatments.

Results Compared to $E_{h o m}, E_{\text {het }}$ increased the final total mass across all species, but did not affect mortality. For species in groups, $E_{\text {het }}$ relative to $E_{\text {hom }}$ decreased the initial total mass of native species, but increased the mass of exotic species, but natives had greater late growth than exotics after $E_{\text {het }}$. $E_{\text {het }}$ also increased the total mass and late growth of mesic species more than xeric and hydric species.

Conclusions Our findings suggest that previous exposure to temporal heterogeneity in water supply may be not beneficial immediately, but can be beneficial for plant late growth and plastic responses under water stress. Species from different habitats, and exotics vs. natives showed contrasting abilities to exploit such benefits from early heterogeneous experience, regardless of their final performance. This revealed the importance of modulating future plastic responses, or "metaplasticity".

\section{Introduction}

Phenotypic plasticity is crucial for organisms that inhabit variable environments (Bradshaw 1965; Pigliucci 2001). Phenotypic plasticity can be a rapid response to the environment (Metlen et al. 2009), but it is also repeated variability, or flexibility, over time as environmental conditions continue to change (Wang et al. 2017). For example, exposure to stressful conditions such as drought or inundation may be harmful to plants, but such previous experiences may subsequently enhance advantageous plastic responses to stress later in the life of an individual (Wang et al. 2017). The influence of plant's past experience on its ability to respond to future environmental conditions (Huber et al. 2012; Niu et al. 2014) has been called "plasticity in plasticity" (Schmid and Weiner 1993), "metaplasticity" (Novoplansky 2009) and "secondary plasticity" (Wang et al. 2017). Such variation in plasticity can clearly contribute to adaptation. For example, contemporary levels of plasticity evolve through selection (Hendry 2016). Thus, this ability or flexibility in modulating the degree of plasticity expressed over time not only reflects conventional strategies of plants in current adaptation to environmental heterogeneity, but also foreshadows their evolution (Hendry 2016).

Since plasticity can evolve as a trait itself (Ackerly et al. 2000; Richards et al. 2006; Via and Lande 1985), phenotypic plasticity has become a key component of ecological evolutionary developmental biology 
(Pfennig 2016). Thus, studies have attempted to understand the evolutionary implications of plasticity (Bradshaw 1965; Ghalambor et al. 2015; Levis and Pfennig 2016; Moczek et al. 2011; Steams 1989), but our understanding of the ecological consequences of plasticity is limited (Fitzpatrick 2012; Miner et al. 2005; Nicotra et al. 2010; Niklaus et al. 2017). Exploring variability in plasticity has the potential to narrow the gap between empirical studies of contemporary, or immediate, plastic responses (Huber et al. 2011; Metlen et al. 2009; Poorter et al. 2012; Wright et al. 2017) and studies that predict how plasticity evolves (Arnold et al. 2019; Chevin and Hoffmann 2017; Levis and Pfennig 2019; Pigliucci 2005; Schlichting 1986).

Highly plastic species are assumed to have an evolutionary history of greater environmental heterogeneity, in either time or space (Alpert and Simms 2002; Baythavong 2011; Bradshaw and Holzapfel 2006; Gianoli and González-Teuber 2005). For individual plants, temporal environmental variation is common (Grant and Grant 2002; Morrissey and Hadfield 2012), with many environmental factors changing repeatedly over a lifespan. There is a large body of literature on plant plasticity expressed among individuals in response to spatial heterogeneity (Hodge 2004; Huber-Sannwald and Jackson 2001; Van Buskirk 2017); reviewed by (García-Palacios et al. 2012), but responses by individuals to temporal heterogeneity have been examined much less (Gianoli and González-Teuber 2005; LázaroNogal et al. 2015), and results are mixed. For example, (De Meester 1996) reported that plasticity in kairomone-induced phototactic responses of Daphnia is higher in lakes with higher temporal variation in fish predation. Similarly, (Gianoli and González-Teuber 2005) found that plasticity in four traits of Convolvulus chilensis was greatest for the population that experienced the greatest temporal variation in nature. (Lázaro-Nogal et al. 2015) found that greater interannual variation in precipitation was correlated with higher plasticity expressed by the semi-arid Chilean shrub, Senna candolleana. In contrast, (Mou et al. 2013) found lower morphological plasticity in response to higher spatial and temporal heterogeneity in nutrients, compared to controls. Phenotypic plasticity itself is not necessarily adaptive, and plastic responses under stressful conditions are often negative or passive (a decrease in mean trait values). If fluctuation in water conditions cause stress to plants, their immediate response should be lower than in moderate water conditions, producing negative plasticity, which is often regarded as nonadaptive or maladaptive. However, a passive response to stress in a trait is not clearly harmful or maladaptive. Regardless, if heterogeneous experiences can improve trait plasticity by alleviating reduction in responses to later stress, such changes in plasticity, or metaplasticity, might be of adaptive significance.

Correlations between temporally variable environments and more plastic sub-populations that occupy them hint at evolutionary causes, and possibly the potential for plants that live in temporally variable habitats to develop greater plasticity in their plasticity (the shift in plasticity). But, there have been very few studies of the effects of prior experiences on plasticity at later stages. Of these studies, early stressful experience has been shown to improve the later performance of plant species under the same stress or different stresses (Wang et al. 2017). This has been referred to as the "priming effect" (Tanou et al. 2012) or "stress memory" (Walter et al. 2013). If plants with such memory can improve tolerance when subjected to the same, different, or even contrary stressful conditions at later stages (Wang et al. 2017), 
previous exposure to temporally heterogeneous conditions may also improve the performance and plastic responses in a trait, perhaps through alleviating its decrease under less favorable environments.

In these contexts, we investigated the effects of prior heterogeneous experiences on the subsequent performance and plasticity in plant mass traits in different water availability treatments. In most environments, plants experience highly fluctuating changes in water conditions at different scales over a single lifespan (D'Odorico and Bhattachan 2012; Parolin et al. 2010). Understanding how early experience with temporal heterogeneity in water availability might affect subsequent plasticity in response to later water supply might reveal important but poorly understood strategies by which plants deal with environmental heterogeneity over their lifespans. Also, species from different habitats may differ in their ability to react and adapt to early heterogeneous experiences (Hendry 2016). For example, species from flooded forests may experience repeated experiences with inundation and drying out, and species from arid environments experience dramatic pulses in water availability (Novoplansky and Goldberg 2001). In addition, exotic invasive species have been hypothesized to show greater phenotypic plasticity than native species (Funk 2008; Hulme 2008; Palacio-López and Gianoli 2011; Richards et al. 2006), but this has not been studied in the context of temporal environmental heterogeneity over time.

Here, we investigated whether and how prior exposure to temporal heterogeneity in water availability affects the subsequent performance and plastic responses to a water gradient for eight species, four exotic invasive species and four native species. We asked the following questions: (1) does early exposure to temporally heterogeneous water supply alter subsequent performance in drought, moderate water and inundation conditions? (2) Does such early exposure affect plant plasticity in response to late drought and inundation, i.e., secondary plasticity? And, (3) Do species from different hydrological habitats and native and exotic species vary in later performance and plasticity in response to early temporally heterogeneous experience?

\section{Materials And Methods}

\section{Study species}

The species we used in this study were the same as in a prior paper (Wang et al. 2017), including four exotic invasive species - Leucanthemum vulgare Lam., Centaurea stoebe L. ssp. micranthos (Gugler) Hayek, Leonurus cardiaca L. and Potentilla recta L., and four native species - Heterotheca villosa (Pursh) Shinners, Gaillardia aristata Pursh, Agastache urticifolia (Benth.) Kuntze and Potentilla arguta Pursh (Wang et al. 2017). Thus, three pairs of exotics and natives shared families and one pair were congeners. All seeds were collected from natural grasslands in western Montana, USA. These species overlap substantially in distributions, but the selected groups of target species generally occur in habitats that share positions on a soil moisture gradient (for details see Wang et al. 2017).

\section{Experimental design}


We conducted the experiment in a greenhouse at the University of Montana, Missoula, Montana. We maintained greenhouse temperatures between $15-30^{\circ} \mathrm{C}$, corresponding roughly to natural summer temperatures in the region. Natural light was supplemented by metal halide bulbs, with maximum total photosynthetically active radiation on clear days reaching $\sim 1200 \mu \mathrm{mol} \mathrm{m} \mathrm{m}^{-2} \mathrm{~s}^{-1}$. Seeds of all species were planted into plastic trays $(54.2 \times 27.3 \mathrm{~cm}$ in width and $6.5 \mathrm{~cm}$ in height) in December 2010 . Two weeks after emergence, individual seedlings were transplanted into pots $(7 \times 7 \mathrm{~cm}$ in width and $20.6 \mathrm{~cm}$ in height) filled with a 1:1 mixture of top garden soil and sterile silica sand. Forty days after transplanting, the length of the longest leaf for each plant was measured, as the initial size of each individual, before the first round of treatments. We implemented a split plot design, with the first round of treatments as a main factor and the second round of treatments and species as sub-factors. There were two "early experience" treatments: alternative inundation-drought as an early heterogeneous treatment $\left(E_{\text {het }}\right)$, and consistent moderate watering as an early homogeneous treatment $\left(E_{h o m}\right.$, control). For each species, a subgroup of plants (20 samples for each species from each early treatment) from these treatments was harvested after 90 days to measure performance during the early stage, and as a reference for calculating "late growth" after the subsequent (or later) treatments. The remaining plants (30 pots for each species in each early treatment) from each of the two early treatment groups ( $E_{\text {het }}$ and $E_{\text {hom }}$ ) were divided into three subgroups (10 for each subgroup), each of which was later exposed to one of the three subsequent treatments: inundation, moderate watering and drought, establishing a gradient of moisture, in the second round (Fig. S1). For each treatment combination in the second round, eight species with ten individuals for each species were used (twenty individuals per species were measured from each treatment in the early treatment). In sum, with one individual per pot, and $20 \times 8 \times 2$ individuals with early treatments only (sampling at the end of the first round) +10 individuals $\times 8$ species $\times 2$ early treatments $\times$ 3 late treatments (sampling at the end of the second round) $=800$ pots in total.

\section{Experimental treatments}

Alternative inundation-drought conditions and moderate water conditions were created using six identical tanks ( $161 \times 91.3 \mathrm{~cm}$ in width, $8.5 \mathrm{~cm}$ in height), with three tanks assigned to each treatment. Tanks were lined with heavy plastic and fit with drains to regulate water depth. The $E_{\text {het }}$ treatment was implemented by first subjecting plants to a round of inundation for two weeks, then another round of drought for another two weeks, followed by two weeks of inundation again, for a total three periods of two-week inundation mixed with two-week drought experiences. There were no intervals between any two rounds of treatments, thus the durations of drought treatments were actually shorter than two weeks, during which soil moisture in pots was not measured. From the observed performances of species, we estimated that the drought treatment did not cause a stress as strong enough as the inundation treatment. Nevertheless, early experience with the temporally heterogeneous hydrological event appeared to cause more stress than the early experience of continuous moderate water conditions. For the $\mathrm{E}_{\mathrm{hom}}$ treatment, we watered each pot daily to capacity, and soil remained moist throughout the experiment. The first round of treatments lasted for 90 days, before the initiation of the second round, in which subsets of plants from each 1st -round treatment were either placed into inundation, moderate water or drought conditions, or 
harvested and measured for evaluating early performance after the heterogeneous treatment (Fig. S2). In the second round of treatments, we also used six tanks to create inundation, drought, and moderate water conditions, with two tanks assigned to each treatment. The duration of the second round of treatments was 60 days. Plants receiving both rounds of treatments were harvested and measured after 150 days, separated into roots and shoots, dried at $60^{\circ} \mathrm{C}$ for two days and weighed.

The inundation, moderate and drought treatments we applied in both rounds of treatments were as similar in greenhouse and hydrological conditions as possible. For the inundation treatment, the water level was maintained at $7 \mathrm{~cm}$ in depth above the bottom of the tank, approximately $10 \mathrm{~cm}$ below the surface of the soil in the pots, and pots were also watered to saturation every day. There was no standing water in the moderate or drought treatment tanks, but in the moderate treatment, pots were watered to saturation every other day. Pots in the drought treatment were watered to saturation once or twice per week. This created periods of standing water in the tanks as we tried to stress plants without killing them.

\section{Statistical analyses}

Mortality rates and total mass for all treatment combinations were calculated. Overall, there were 720 individuals surviving at the end of the experiment, which were used for analyses. Traits of total mass, shoot mass and root mass and root to shoot ratio were used to assess the performance of species. Late growth (LG) for shoot mass, root mass and total mass of each species for all early - late treatment combinations was calculated with the formula (Wang et al. 2017):

$\mathrm{LG}=(Y-X) / X(1)$

where $X$ is the mean trait value of 20 individuals from each early treatment (early response group), and $Y$ is the mean trait value in the late treatment of 10 individuals from the same early treatment as the early response group. For example, to calculate the LG for total biomass in late drought for a species with early heterogeneous experience, $X$ is the mean total mass of individuals with early heterogeneous experience and $Y$ is the mean value of individuals in the late drought with early heterogeneous experience.

Mean values of shoot mass, root mass and total mass were log-transformed, and mortality rates were square root-transformed, to minimize variance heterogeneity. The $\mathrm{r}^{2}$ values derived from models for ANCOVA analyses on shoot mass, root mass, total mass and root to shoot ratio were higher with species as a variable than models with habitat type and nativity (native vs. exotic) as variables. However, due to significant effects of habitat type and nativity on traits, we used the analytic results of ANOVAs or ANCOVAs with the two factors as variables. For individuals that only received one round of treatments, three-way ANCOVA was conducted to evaluate effects of the first round of treatments, habitat type, nativity and their interactions on four traits, including shoot mass, root mass, total mass and root to shoot ratios. The initial size (the length of the longest leaf per individual) of individuals was used as a covariate (the same covariate was applied in the following ANCOVAs). For those with two rounds of treatments, we used four-way ANCOVA for mean values of shoot mass, root mass, total mass and root:shoot ratio (with initial size as a covariate), and four-way ANOVA for mortality, late growth values (of 
shoot mass, root mass and total mass), with the first and (or) second treatment rounds, habitat type, nativity, and their interactions as effects, since there were not enough degrees of freedom to analyse the effects of individual species on these variables. All dependent variables were then analysed with one-way ANCOVA or ANOVA for the effects of early experience for each or all species, for each or all late treatments, and differences among different groups of species within each of or across all the other treatments. Adjusted mean values for all four traits including total mass, shoot mass, root mass and root:shoot ratio were also produced from one-way ANCOVA in General Linear Model (GLM, for the effects of late treatments on mean values after removal of size effects), to calculate the plasticity in traits.

Adjusted mean values were then used for these traits to calculate the degree of trait plasticity in response to late water conditions. Plasticity for mean values in a given trait was calculated using the Simplified Relative Distance Plasticity Index (Valladares et al. 2006) as:

$\operatorname{RDPI}_{\mathrm{S}}=\left(Y_{2}-Y_{1}\right) / Y_{1}(2-1)$

Another index of plasticity $(\mathrm{PI})$ was used for late growth because the late growth values were already relative by calculation. $\mathrm{PI}$ for late growth in a given trait was calculated as:

$\mathrm{PI}=Y_{2}-Y_{1}(2-2)$

where $Y_{2}$ represented mean trait values for each species in inundation or drought after early heterogeneous or homogeneous treatments, and $Y_{1}$ represented mean trait values in moderate water treatments after the same early treatments. For any individual or group of species, to compare effects of early inundation and drought treatments on their subsequent responses, we defined "difference variables" ('Diff-', Wang et al. 2017), as the difference in the mean trait values between individuals from the early homogeneous treatment $\left(E_{\text {hom }}\right)$ and the early heterogeneous treatment $\left(E_{\text {het }}\right)$ :

Diff- $Y=Y_{\text {het }}-Y_{\text {hom }}$

where Diff- $Y$ was the difference in late performance between individuals after the early timeheterogeneous treatment $\left(E_{\text {het }}\right)$ and those after the early time-homogeneous treatment $\left(E_{\text {hom }}\right)$ for a trait of a species. For a given species, $Y_{\text {hom }}$ was the mean trait value in a late condition after $E_{h o m}$ (control) and $Y_{\text {het }}$ was its mean trait value in the same late condition after $E_{\text {het }}$. For example, to calculate the Diff-TM (difference in total mass) due to $E_{\text {het }}$ in late drought for a species, $Y_{\text {hom }}$ is its mean total biomass in late drought after $E_{h o m}$, and $Y_{\text {het }}$ is its mean total biomass in late drought after $E_{\text {het }}$.

For a given trait, Diff-values due to early treatments were regarded as significant when its mean values (in the same late conditions) differed between two early treatments at 0.10 level (LSD method in one-way ANOVA). The degree of plasticity was regarded as significant when mean values of two late water treatments differed significantly at 0.05 level (LSD method in one-way ANOVA). Diff-values and plasticity for all traits were also analysed with three-way ANOVA, with the first (for plasticity) or second (for Diffvalues) treatment rounds, habitat type, nativity, and their interactions as effects. One-way ANOVA was 
used to analyze effects of the $1 \mathrm{st}$-round/2nd -round treatments on the plasticity and Diff-values for all traits as well as differences among groups of species in them, for each species and across all and within groups of species. The LSD method was used for multiple comparisons of mean values for mortality, mass traits and their late growth, as well as Diff-values and plasticity in all traits among the 1 st -round treatments (if available), among the 2nd -round treatments (if available), among different habitat types and between exotic and native species, within each of or across all the other treatments.

\section{Results}

\section{Mortality}

The habitat type in which species occurred was the only factor that affected mortality rate, which was also affected by interactions between habitat type and nativity, and between the 2 nd -round treatments and nativity (Table 1). Across all species and treatments, mortality was $4.7 \%$ by the end of the first round of treatments and $11.5 \%$ after the second round, but these rates did not differ (ANOVA, $F=2.0 ; d f=1,63 ; P$ $=0.162$; Fig. 1; Fig. S3 in the Supplementary Material). Considering individual species, the mortality of $H$. villosa, G. aristata, A. urticifolia (all of these are native species) in late inundation ranged from $2 \sim 8 \%$ after early homogeneous experience $\left(E_{\text {hom }}\right)$, higher than that following an early heterogeneous experience for these species $\left(E_{\text {het; }} ; \mathrm{F}=4.9 ; \mathrm{df}=1,9 ; P=0.047 ; \mathrm{Fig}\right.$. $\mathrm{S} 3$ in the Supplementary Material). 
Table 1

F-values for three-way and four-way ANCOVAs for effects of 1st round (1st) and/or 2nd round (2nd ) of treatments, habitat type (HA), nativity (NA) and their interactions. Analyses were performed on Sqt (mortality rate [MR]), $\log _{10}$ (shoot mass [SM]), $\log _{10}$ (root mass [RM]), $\log _{10}$ (total mass [TM]) and $\log _{10}$ (root: shoot [R/S])), for all plants subjected to the first round of treatments, and those subjected to two rounds of treatments. $\log _{10}$ (initial size [IS]), as a covariate, was nested in the species effect in ANCOVAs. Significance levels are: ${ }^{*} P<0.05$, ** $P<0.01$, *** $P<0.001$.

\begin{tabular}{|c|c|c|c|c|c|c|}
\hline Source & df & MR & $\log _{10}(\mathrm{SM})$ & $\log _{10}(\mathrm{RM})$ & $\log _{10}(T M)$ & $\log _{10}(R / S)$ \\
\hline \multicolumn{7}{|c|}{ After the 1 st round } \\
\hline $\log _{10}(\mathrm{IS})$ & 1 & 0.562 & $127.47 * \star \star$ & $226.49 * \star \star$ & $205.25^{\star \star \star}$ & $143.45^{\star \star \star}$ \\
\hline 1 st & 1 & 0.134 & $5.12 *$ & 1.52 & 2.08 & 1.31 \\
\hline $\mathrm{HA}$ & 2 & 2.407 & $18.12^{\star \star \star}$ & $35.88 * \star \star$ & $30.70 * \star *$ & 29.41 ** \\
\hline NA & 1 & 3.105 & $28.79 * \star \star$ & 0.08 & $4.31 *$ & $63.83^{* \star \star}$ \\
\hline 1 st $\times \mathrm{HA}$ & 2 & 0.018 & 2.58 & $6.32 * \star$ & $5.27 * \star$ & $6.24 * \star$ \\
\hline $1 \mathrm{st} \times \mathrm{NA}$ & 1 & 0.184 & $5.03^{*}$ & 2.36 & $4.02 *$ & 0.26 \\
\hline $\mathrm{HA} \times \mathrm{NA}$ & 2 & 0.383 & 16.74 ** & $12.45^{\star \star \star}$ & $8.44 * \star \star$ & $75.46 * \star \star$ \\
\hline \multicolumn{7}{|c|}{ After the 2 nd round } \\
\hline $\log _{10}(\mathrm{IS})$ & 1 & 0.280 & $62.66^{\star \star \star}$ & $130.43^{\star \star \star}$ & $120.59 * \star \star$ & $41.91^{\star \star \star}$ \\
\hline 1 st & 1 & 0.025 & $5.01 *$ & 14.44 *** & $13.08 * \star \star$ & $4.93^{*}$ \\
\hline 2nd & 2 & 2.356 & $4.79 * \star$ & $54.92 * \star *$ & $37.21 * \star \star$ & $53.19 * * *$ \\
\hline $\mathrm{HA}$ & 2 & $7.604^{\star \star}$ & $17.44^{\star \star \star}$ & $107.33^{* \star \star}$ & $51.08 * \star \star$ & $159.28 * \star \star$ \\
\hline NA & 1 & 1.854 & $97.36 * \star \star$ & $83.70 * \star \star$ & $85.88 * \star \star$ & 3.17 \\
\hline $1 \mathrm{st} \times 2 \mathrm{nd}$ & 2 & 1.831 & 0.76 & 0.73 & 0.82 & 0.17 \\
\hline 1 st $\times \mathrm{HA}$ & 2 & 0.059 & 3.14 & $4.38 *$ & $3.64^{*}$ & $6.30 * *$ \\
\hline 1 st $\times$ NA & 1 & 1.088 & $13.39 * \star *$ & 18.52 *** & 15.81 *** & $12.65^{\text {*** }}$ \\
\hline $2 \mathrm{nd} \times \mathrm{HA}$ & 4 & 0.481 & 1.61 & 0.47 & 1.81 & 0.72 \\
\hline $2 n d \times N A$ & 2 & 2.525 & 5.40 & 7.84 *** & $6.99 * *$ & 1.05 \\
\hline $\mathrm{HA} \times \mathrm{NA}$ & 2 & 0.961 & $7.49 \star * \star$ & $24.27 * \star \star$ & 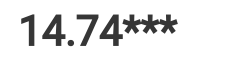 & 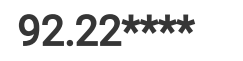 \\
\hline
\end{tabular}

After the 1st round of treatments (early experience), and across both early experience treatments, native species had higher mortality than exotic species $(\mathrm{F}=4.4 ; \mathrm{df}=1,15 ; P=0.055 ; \mathrm{Fig} .2)$, and species from xeric habitats had higher mortality than species from mesic habitats (LSD, $P=0.036$; Fig. 3). After the 2nd round of treatments, there was no difference in mortality between natives and exotics (Fig. 2); but species 
from hydric habitats suffered higher mortality (32.5\%) than species from other habitats $(4.4 \%)$, across both early experience treatments $(F=13.8 ; \mathrm{df}=1,95 ; P<0.001 ;$ Fig. 3$)$.

\section{Total biomass and its allocation}

Across all species and treatments, after the 1st round of treatments, for total mass and root:shoot ratio, the effects of early experience (the 1st -round treatments) were not significant, but the effects of habitat type and species nativity (exotic vs. native), and their interaction, as well as interactions between early experience and habitat type were significant (Table 1). The interaction between early experience and nativity was also significant for total mass. After the 1 st round of treatments, early experience did not affect mean total mass of all species combined (Fig. 1). However, $E_{\text {het }}$, relative to $E_{\text {hom, }}$ increased the total mass of exotic species (ANCOVA, $\mathrm{F}=3.87 ; \mathrm{df}=1,156 ; P=0.051)$ and decreased that of native species $(\mathrm{F}=$ $4.89 ; \mathrm{df}=1,146 ; P=0.029 ; \mathrm{Fig} .2)$. $\mathrm{E}_{\text {het }}$ also increased the total mass of species from hydric habitats $(\mathrm{F}=$ 8.03; $\mathrm{df}=1,78 ; P=0.006)$, decreased root:shoot ratios of mesic species $(\mathrm{F}=5.92 ; \mathrm{df}=1,155 ; P=0.016$; Fig. 3). Exotics had higher total mass and lower root:shoot ratios than natives after $E_{\text {het }}(F=16.03$ and 9.69; $\mathrm{df}=1,151 ; P<0.001$ and $P=0.002$ for total mass and root:shoot ratio respectively; Fig. 2$)$. Species from hydric habitats had lower total mass, and mesic species had higher root:shoot ratios, than other species across $\mathrm{E}_{\text {het }}$ and $\mathrm{E}_{\text {hom }}$ combined (Fig. 3; $P<0.001$ ).

After the 2 nd round of treatments, the effects of early experience, late conditions, habitat type and nativity (exotic vs. native) were significant for most cases, with significant interactions between 1st round and nativity, and between habitat type and nativity (Table 1). Across all species, after the second round, $E_{\text {het }}$ relative to $\mathrm{E}_{\mathrm{hom}}$, increased total mass by $10.6 \%$ (ANCOVA, $\mathrm{F}=6.7 ; \mathrm{df}=1,412 ; P=0.010$; Fig. 1 ). In terms of Diff-TM (difference in total mass between $E_{\text {het }}$ and $E_{\text {hom }}$ ) of individual species, total mass in late moderate or inundation conditions was significantly higher after $E_{\text {het }}$ than after $E_{h o m}$, producing a positive Diff-TM for exotic species from mesic and hydric habitats (P. recta, $L$. cardiaca and $L$. vulgare, $P<0.05$; Fig. $S 5$ in the Supplementary Material). $E_{\text {het }}$ increased the total mass of exotic species $(F=7.22 ; d f=$ 1,218; $P=0.008$ ), but not that of native species (Fig. 2). $E_{\text {het }}$ increased the total mass of species from mesic $(\mathrm{F}=7.02 ; \mathrm{df}=1,227 ; P=0.009)$ and hydric $(\mathrm{F}=7.00 ; \mathrm{df}=1,80 ; P=0.01)$ habitats, and the root:shoot ratios of mesic species ( $\mathrm{F}=9.57$; $\mathrm{df}=1,227 ; P=0.002$; Fig. 3; Fig. $\mathrm{S} 3$ in the Supplementary Material). Across both $E_{\text {het }}$ and $E_{h o m}$, exotics had higher total mass than natives $(F=22.93 ; \mathrm{df}=1,412 ; P<0.001$; Fig. 2); xeric species had lower total mass and root:shoot ratio than other species ( $F=41.57$ and 57.32 for total mass and root:shoot ratio respectively; $\mathrm{df}=2,413 ; P<0.001 ;$ Fig. 3 ).

\section{Late growth}

All factors, and most interactions between factors, had significant effects on late growth (growth during the 2 nd round of treatments) of all three traits (Table 2), and the effects of habitat type and nativity were also significant for the difference in late growth of total mass (Diff- $\mathrm{LG}_{\mathrm{TM}} ;$ Table 3). Across all late treatments, in comparison to $E_{\text {hom }}$, $E_{\text {het }}$ tended to improve late growth for total mass $\left(L_{\mathrm{TM}}\right)$ of native species $(\mathrm{F}=3.5 ; \mathrm{df}=1,23 ; P=0.077)$ and for species from mesic habitats $(\mathrm{F}=6.8 ; \mathrm{df}=1,23 ; P=0.016)$, with positive Diff-values (Fig. 2-4). For individual species, $E_{\text {het }}$ increased late growth from an average of 
$59.60-114.5 \%$ of $\mathrm{LG}_{\mathrm{TM}}$ for native species from xeric and mesic habitats (H. villosa, G. aristata and $P$. arguta) under all late conditions ( $\mathrm{F}=8.06 ; \mathrm{df}=1,53 ; P=0.006$; Fig. $\mathrm{S} 4$ in the Supplementary Material). In contrast, $\mathrm{E}_{\text {het }}$ decreased late growth for the exotic hydric species, L. cardiac, after late drought from $126.5-11.5 \%(\mathrm{~F}=18.24 ; \mathrm{df}=1,5 ; P=0.013)$.

Table 2

F-values for four-way ANOVA for the effects of the 1st and 2 nd rounds of treatments (1st, 2 nd ), habitat type

$(\mathrm{HA})$, nativity (NA) and their interactions, on late growth of shoot mass, root mass and total mass $\left(\mathrm{LG}_{\mathrm{SM}}, \mathrm{LG}_{\mathrm{RM}}, \mathrm{LG}_{\mathrm{TM}}\right)$, for plants that had been subjected to two rounds of treatments. Significance levels are: * $P<0.05$, ** $P<0.01$, *** $P<0.001$.

\begin{tabular}{|c|c|c|c|c|}
\hline Source & df & $\mathrm{LG}_{\mathrm{SM}}$ & $L_{\mathrm{RM}}$ & $\mathrm{LG}_{\mathrm{TM}}$ \\
\hline 1st & 1 & 2.88 & $8.47 *$ & $11.67^{* *}$ \\
\hline $2 n d$ & 2 & $9.27 * \star$ & $34.29 * \star \star$ & $25.27^{* \star \star}$ \\
\hline $\mathrm{HA}$ & 2 & 55.31 *** & 13.61 *** & $44.93^{* \star \star}$ \\
\hline NA & 1 & $48.26 * \star \star$ & 2.69 & $25.48^{* \star \star}$ \\
\hline $1 \mathrm{st} \times 2 \mathrm{nd}$ & 2 & 0.22 & 0.30 & 0.37 \\
\hline 1 st $\times \mathrm{HA}$ & 2 & 3.01 & $5.06 *$ & $4.16 *$ \\
\hline 1 st $\times$ NA & 1 & 8.16 ** & $8.23^{* *}$ & $6.52 * *$ \\
\hline $2 \mathrm{nd} \times \mathrm{HA}$ & 4 & 10.25 ** & 17.71 ** & $25.52^{* \star \star}$ \\
\hline $2 n d \times N A$ & 2 & $4.48^{*}$ & 3.66 & 2.90 \\
\hline $\mathrm{HA} \times \mathrm{NA}$ & 2 & $28.36 * \star \star$ & $12.52^{\star \star}$ & $30.38 * * \star x$ \\
\hline
\end{tabular}


Table 3

F-values for three-way ANOVA for effects of the 2nd round (2nd ) of treatments, habitat type (HA), nativity (NA) and their interactions on the differences due to early experience (Diff-values). Effects are presented for mean shoot mass (Diff-SM), root mass (Diff-RM), total mass (Diff-TM) and root: shoot

(Diff-R/S), and the relative growth of shoot mass (Diff- $\mathrm{LG}_{\mathrm{SM}}$ ), root mass (Diff-LG $\mathrm{RM}_{\mathrm{RM}}$ ) and total mass (Diff-LG $\left.\mathrm{G}_{\mathrm{TM}}\right)$, for plants that had been subjected to two rounds of treatments. Significance levels are: * $P$ $<0.05, * \star P<0.01, * \star \star *<<0.001$.

\begin{tabular}{|c|c|c|c|c|c|c|c|c|}
\hline Source & df & Diff-SM & Diff-RM & Diff-TM & Diff-R/S & Diff-LG ${ }_{S M}$ & Diff-LG ${ }_{R M}$ & Diff-LG ${ }_{T M}$ \\
\hline 2nd & 2 & 0.308 & 0.866 & 0.659 & 3.031 & 0.484 & 2.482 & 2.431 \\
\hline $\mathrm{HA}$ & 2 & 0.712 & 3.023 & 1.381 & 2.192 & 3.595 & 12.826 ** & $7.461^{*}$ \\
\hline NA & 1 & 0.460 & 0.476 & 0.22 & 1.846 & $16.369 * *$ & $52.226 * \star \star$ & $54.337 * \star \star$ \\
\hline 2nd $\times \mathrm{HA}$ & 4 & 0.303 & 2.235 & 1.349 & $5.716^{*}$ & 0.833 & $7.492^{*}$ & $4.930 *$ \\
\hline $2 n d \times N A$ & 2 & 0.246 & 0.236 & 0.072 & $5.581^{*}$ & 0.684 & 1.159 & 0.492 \\
\hline $\mathrm{HA} \times \mathrm{NA}$ & 2 & 0.250 & 2.895 & 1.520 & 4.135 & 4.811 & 3.98 & $6.083^{*}$ \\
\hline
\end{tabular}

Across both early experience treatments, late inundation, relative to moderate and drought conditions, increased the $L_{T}$ of hydric species (LSD, $P<0.05$ ). Across all late conditions after $E_{\text {het, }}$, native species had higher late growth (LSD, $P<0.05$; Fig. 2) and higher Diff-values (difference in $L_{\mathrm{TM}}$ between $E_{\text {het }}$ and $\left.E_{\text {hom }} ; \mathrm{F}=15.88 ; \mathrm{df}=1,23 ; P<0.001 ; \mathrm{Fig} .4\right)$, than exotic species. Across the two early experiences and all late conditions, xeric species had higher late growth than species from other habitats $(F=8.08 ; \mathrm{df}=2,47$; $P=0.001$; Fig. 3), while species from hydric habitats had lower Diff-values in late growth than other species (LSD, $P<0.05$; Fig. 4).

Plasticity in mass traits and late growth

The effects of early experience were not significant across all species considered together for plasticity in mean trait values and late growth rates (Table S2 in the Supplementary Material). However, relative to $E_{\text {hom }}, E_{\text {het }}$ increased plastic responses to late drought in root:shoot ratios for mesic species $(F=9.53 ; d f=$ $1,7 ; P=0.021)$, but did not affect plasticity in response to inundation for any trait of any group of species (Fig. 5). For individual species, the effects of $E_{\text {het }}$ vs. $E_{\text {hom }}$ on plasticity to drought were significant in more species than on plasticity to inundation (Table 4; Fig. S6, S7 in the Supplementary Material). Compared to $\mathrm{E}_{\text {hom, }}, \mathrm{E}_{\text {het }}$ increased plastic responses to inundation in mass traits and their late growth for L. vulgare and $A$. urticifolia $(P<0.05)$; increased plastic responses to drought in these traits for $L$. vulgare and $G$. aristata $(P<0.01)$, but decreased their plastic responses to drought of $L$. cardiaca and $P$. recta $(P<$ $0.01)$. Species from xeric and hydric habitats generally had less negative plasticity in traits $(F=60.15$ and 13.68 for xeric and habitat species respectively; $\mathrm{df}=1,23 ; P<0.001$ ) in response to drought than to inundation (Fig. 5). 
Table 4

F-values for one-way ANOVAs for the effects of the 1st rounds of treatments on plasticity to inundation and drought for shoot mass, root mass, total mass $\left(\mathrm{RDPI}_{\mathrm{s}}\right.$ ) and their late growth (PI) for each species that

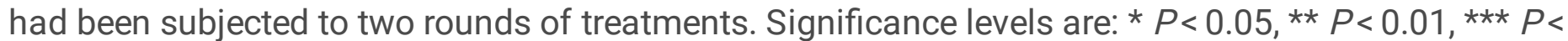
0.001 .

\begin{tabular}{|c|c|c|c|c|}
\hline \multirow[b]{2}{*}{ Species } & \multicolumn{2}{|c|}{ Plastic response to inundation } & \multicolumn{2}{|c|}{ Plastic response to drought } \\
\hline & $\begin{array}{l}\mathrm{RDPI}_{\mathrm{s}} \text { for mean } \\
\text { value }\end{array}$ & $\begin{array}{l}\text { PI for mean } \\
\text { LG }\end{array}$ & $\begin{array}{l}\mathrm{RDPI}_{\mathrm{S}} \text { for mean } \\
\text { value }\end{array}$ & PI for mean LG \\
\hline Centaurea & 0.067 & 0.37 & 0.983 & 6.496 \\
\hline Heterotheca & 6.327 & 0.711 & 3.62 & 1.84 \\
\hline Leucanthemum & $60.949 * *$ & $142.912^{\star \star \star}$ & $56.523 * *$ & $64.794 * \star$ \\
\hline Potentilla recta & 4.72 & 3.204 & $23.689 * *$ & $35.218^{* *}$ \\
\hline Gaillardia & 0.313 & 3.866 & $103.457^{* *}$ & $603.852^{\star \star \star}$ \\
\hline $\begin{array}{l}\text { Potentilla } \\
\text { arguta }\end{array}$ & 2.545 & 5.304 & 0.783 & 1.519 \\
\hline Leonurus & 4.965 & 0.127 & 74.951 ** & $44.587 * \star$ \\
\hline Agastache & $27.036 * *$ & $9.724^{*}$ & 3.443 & 0.248 \\
\hline
\end{tabular}

\section{Discussion}

Our most important finding was that temporally heterogeneous experiences $\left(E_{\text {het }}\right)$ early in the lives of plants were often beneficial to their later performance, although immediate effects were adverse for several species. We found very few negative effects of early heterogeneous experiences. Generally, $E_{\text {het }}$ reduced mortality in later conditions and improved performance (measured in a number of ways) and late growth in total biomass in various later environmental treatments. The effects of early environmental heterogeneity were different in extent for species, suggesting different adaptive strategies. $E_{\text {het }}$ decreased the total mass of native species from mesic habitats immediately, but improved their late growth in total mass later; in contrast, it improved the immediate total mass of exotic species, and did not affect their late growth.

\section{Adaptive later response to early heterogeneous experience}

The stress induced by our inundation and drought treatments was not severe enough to increase mortality more than that in moderate conditions. However, mean total biomass of species was decreased by early experience of water fluctuation and late inundation. Additionally, most species, whether exposed to heterogeneous or homogenous treatments, performed more poorly in later inundation than later moderate water (control) and drought conditions, suggesting inundation was more stressful than drought. The drought treatments we set up in the first round of treatments (testing for effects of 
temporally heterogeneous water supply) might not have been severe enough prior to the second round of water treatments. If so, this may have mitigated the adverse effects of drought treatment in the second round. Even so, several species showed reduced survival, shoot mass, root mass or total mass in late drought, in comparison to control, after either early experience. Thus, our drought treatments in either the first round of temporally heterogeneous experience or the second round of late water conditions should have caused stress to our species. Such drought and inundation stress in the early heterogeneous water treatment may have promoted the late growth of different species to different extents, so that their final performance was less negatively affected. This suggests that plants not only can benefit from a single extreme hydrological experience (inundation or drought) (Wang et al. 2017), but also may be able to react positively to alternating inundation and drought. Heterogeneous experiences may improve plant total mass via promoting increased root:shoot ratios, as a larger root system should be essential for adaptation to either late drought or inundation conditions (Wang et al. 2017), and is consistent with studies on plant response to drought (Eziz et al. 2017; Poorter et al. 2012).

Models predict that spatial variation more strongly favors plasticity in traits than temporal variation (Scheiner 2013). However, they also found that among-generation temporal heterogeneity favors plasticity, whereas heterogeneity within the span of one generation should also favor plasticity if environmental changes are highly correlated. We found that the alternating drought-inundation treatment delivered the same duration and frequency of these experiences, and appeared to provide reliable signals to plants. This may explain why temporally heterogeneous experiences promoted plant later growth, though not higher plasticity. The two ends of water gradient, inundation and drought, may have sent signals that elicited the same responses (Wang et al. 2017). Consequently, response to either stress may have conferred an advantage to species in dealing with both stresses in later growth stages, though it was not beneficial immediately.

\section{Species from different habitats}

Only species from mesic habitats, as a group, showed improved late growth after early heterogeneous vs. homogeneous experience. This result contrasted with other reports of decreases in late growth after early extreme experiences (Wang et al. 2017). This contrast might be explained by several factors. First, a single extreme experience may not have the same effect of heterogeneity in water availability over time. Second, mesic species were better able to deal with the adverse effects of inundation (more stressful than drought in this study), but were more vulnerable to drought, which was not as detrimental as in (Wang et al. 2017). Third, heterogeneous water supply provided an intermediate amount of water, which may have benefitted mesic species more than species from other habitats. The third explanation is consistent with the observation that the habitat in which a species occurs can play an important role for determining metaplasticity in response to early experiences (Wang et al. 2017). Nevertheless, mesic species may not lack a history of adaptation to extreme environments in general, but may have a limited ability to tolerate stress. In variable environments, mesic species may tend to adopt "bet-hedging" strategies, which indicate the ability to maintain stable performances in stressful environments, but limited growth potential in benign environments. Finally, temporally heterogeneous environmental 
changes might have stimulated phenotypic canalization, especially in traits important to fitness, such as total mass, which can be adaptive to highly variable environments (Debat and David 2001; Liefting et al. 2009; Stearns et al. 1995; Wagner et al. 1997).

Species from hydric habitats suffered higher mortality and gained fewer benefits from early heterogeneous experience than those from other habitats. This may be because species from hydric habitats have adapted to habitats with a relatively narrow range of variation in water availability, and are less likely to encounter drought and thus exceptionally heterogeneous water conditions over their lifetimes. Interestingly, xeric species did not show lower tolerance to inundation than species from mesic or hydric habitats, in terms of late growth, and even showed greater late growth in late moderate water and drought conditions than other species from other habitats after either early experience. Since performance in mass traits was an additive result of both early growth and late growth, lower mass traits do not represent lower overall growth potential. These suggested that xeric species are able to adapt a wider range of water conditions than other species.

For plasticity, the effects of early experience were less dependent on the habitat type of species or the nativity of species. For example, $E_{\text {het }}$ increased the plastic response to inundation for $L$. vulgare and $A$. urticifolia, but increased the plastic response to drought for $L$. vulgare and G. aristata, and decreased this plastic response for $L$. cardiaca and $P$. recta. Nevertheless, the lower plasticity shown in response to late inundation expressed by hydric and xeric species was a result of much better performances under late moderate conditions, rather than lower performances when inundated. Therefore, mesic species and species from more-extreme habitats showed adaptive changes in plasticity due to early heterogeneous experience.

\section{Exotic versus native species}

There were no differences in late plasticity between exotic and native species, and these species did not differ in how plasticity changed in response to early experience in general. However, exotic and native species differed in their later performances in response to early heterogeneous experiences, revealing potentially contrasting adaptive strategies. For example, we found that exotic species were larger in total mass than native species (after removal of effects of their initial sizes) immediately and in late conditions after early heterogeneous experience. This suggests that exotics may respond more rapidly to environmental variability than natives (Davidson et al. 2011; Richards et al. 2006). However, this early growth appeared to come at the cost of lower later growth for exotics after early heterogeneous experience. This may have revealed a kind of "plasticity-history limit" (van Kleunen and Fischer 2005; Weinig and Delph 2001) demonstrated by exotic species, which may invest in expenditures which reduces the potential to improve growth rates in the future. The limits of plasticity include information reliability, lag times, developmental range limit and plasticity-history limit (Givnish 2002; van Kleunen and Fischer 2005). Many studies have focused on the costs and benefits of plasticity, but the corresponding limits are seldom reported (Donohue et al. 2000; Murren et al. 2015; Relyea and Yurewicz 2002; Van Buskirk and Steiner 2009; Weijschedé et al. 2006). 
In contrast, native species showed greater late growth and greater improvement in late growth after temporally heterogeneous experiences than exotic species, implying that immediate plastic responses that appear to be disadvantageous do not necessarily mean a permanent disadvantage, even over the lifetime of a single individual. Environment-driven decreases in performance may even render future benefits in the long term.

\section{Costs and benefits of plasticity}

There are several types of costs associated with plasticity. These include maintenance costs, production costs, information acquisition costs, genetic costs and developmental instability costs (DeWitt et al. 1998). The "plasticity-history limit", manifest by exotic species also appears to be a cost of plasticity, as maintaining performance in a temporally heterogeneous environment might come at the cost of reduced growth rates later in life. Such costs are rarely detected, probably because studies usually focus on contemporary plasticity in response to different environmental treatments, and not on the long-term consequences of plasticity. Another reason for the difficulty in detecting costs of plasticity (DeWitt et al. 1998; Valladares et al. 2007) might be that costs and benefits occur simultaneously, either for a given trait, an organism or a species (Weijschedé et al. 2006). For example, compared to the least plastic phenotypes, species with greater phenotypic plasticity may survive stressful conditions and insure normal growth and reproduction in the future via adjusting numerous traits, leading to benefits compared to non-plastic ones. Such benefits may counteract costs associated with plasticity (Scheiner and Berrigan 1998; Sultan and Spencer 2002). The overall results may often be neutral or slightly beneficial. More importantly, in the long term, a currently passive or non-active plastic response to an environmental event produced by species may be compensated by future benefits. This was shown well by adaptation of native species to early heterogeneous water conditions.

\section{Conclusions}

Temporally heterogeneous experiences were beneficial, or at least not harmful, for species in many cases, relative to temporally homogeneous experiences. For species grouped by different habitats, the effects of early temporally heterogeneous experience improved the late growth of mesic species, but was less beneficial for hydric and xeric species. For exotic vs. native species, early temporally heterogeneous experience was more beneficial for the latter, suggesting different strategies in dealing with heterogeneous environments. Our results demonstrated the value of studies of secondary plasticity, which provides understanding of plant plasticity in a long-term perspective. We provided perspective on this by examining how early environmental experiences may alter plant subsequent responses to environmental conditions, which in turn may contribute to costs and limits of plasticity. The implications of how temporally variable experiences affect plant growth may be substantially underestimated, and deserve attention in the future.

\section{Declarations}

Supplemental Information The online version contains supplementary material available at 


\section{Supporting information}

Additional Supporting Information may be found in the online version of this article.

Tables S1, S2; Figs. S1-S7.

Acknowledgements: Comments by reviewers and editors helped to improve the manuscript.

Author contributions: Formulated the idea of the manuscript and designed the experiment: SW, RMC. Carried out the experiment and wrote the first draft of the manuscript: SW. Commented and edited the manuscript: RMC, SW.

Funding: This research was financially supported by the National Science Foundation EPSCoR Cooperative Agreement OIA-1757351 and the International Programs at the University of Montana to RMC, and the National Natural Science Foundation of China (NSFC, grant No. 31800335), Guizhou Province Science and Technology Department Program (2019-1089), and Guizhou University Talent Introduction Research Program (2017-39) to SW.

Conflict of interest: The authors declare that they have no known competing financial interests or personal relationships that could have appeared to influence the work reported in this paper.

Data Accessibility: All data is present in the paper and its supporting information.

\section{References}

1. Ackerly D, Dudley S, Sultan SE, Schmitt J, Coleman J, Linder CR, Sandquist DR, Geber MA, Evans AS, Dawson E, Lechowic M (2000) The evolution of plant ecophysiological traits: recent advances and future directions. Bioscience 50:979-995

2. Alpert $P$, Simms EL (2002) The relative advantages of plasticity and fixity in different environments: when is it good for a plant to adjust? Evol Ecol 16:285-297

3. Arnold PA, Nicotra AB, Kruuk LE (2019) Sparse evidence for selection on phenotypic plasticity in response to temperature. Philosophical Transactions of the Royal Society B 374:20180185

4. Baythavong BS (2011) Linking the spatial scale of environmental variation and the evolution of phenotypic plasticity: selection favors adaptive plasticity in fine-grained environments. Am Nat 178:75-87

5. Bradshaw AD (1965) Evolutionary significance of phenotypic plasticity. Adv Genet 13:115-155

6. Bradshaw WE, Holzapfel CM (2006) Climate change. Evolutionary response to rapid climate change. Science 312:1477-1478

7. Chevin LM, Hoffmann AA (2017) Evolution of phenotypic plasticity in extreme environments. Philosophical Transactions of the Royal Society B: Biological Sciences 372:20160138 
8. D'Odorico P, Bhattachan A (2012) Hydrologic variability in dryland regions: impacts on ecosystem dynamics and food security. Philosophical Transactions of the Royal Society B: Biological Sciences 367:3145-3157

9. Davidson AM, Jennions M, Adrienne B, Nicotra AB (2011) Do invasive species show higher phenotypic plasticity than native species and, if so, is it adaptive? A meta-analysis. Ecol Lett 14:419431

10. De Meester L (1996) Evolutionary potential and local genetic differentiation in a phenotypically plastic trait of a cyclical parthenogen, Daphnia magna. Evolution 50:1293-1298

11. Debat V, David P (2001) Mapping phenotypes: canalization, plasticity and developmental stability. Trends in Ecology Evolution 16:555-561

12. DeWitt TJ, Sih A, Wilson DS (1998) Costs and limits of phenotypic plasticity. Trends in Ecology Evolution 13:77-81

13. Donohue K, Messiqua D, Pyle EH, Heschel MS, Schmitt J (2000) Evidence of adaptive divergence in plasticity: density- and site-dependent selection on shade-avoidance responses in Impatiens capensis. Evolution 54:1956-1968

14. Eziz A, Yan Z, Tian D, Han W, Tang Z, Fang J (2017) Drought effect on plant biomass allocation: A meta-analysis. Ecology evolution 7:11002-11010

15. Fitzpatrick BM (2012) Underappreciated consequences of phenotypic plasticity for ecological speciation. International Journal of Ecology

16. Funk JL (2008) Differences in plasticity between invasive and native plants from a low resource environment. J Ecol 96:1162-1175

17. García-Palacios P, Maestre FT, Bardgett RD, De Kroon H (2012) Plant responses to soil heterogeneity and global environmental change. J Ecol 100:1303-1314

18. Ghalambor CK, Hoke KL, Ruell EW, Fischer EK, Reznick DN, Hughes KA (2015) Non-adaptive plasticity potentiates rapid adaptive evolution of gene expression in nature. Nature 525:372-375

19. Gianoli E, González-Teuber M (2005) Environmental heterogeneity and population differentiation in plasticity to drought in Convolvulus chilensis (Convolvulaceae). Evol Ecol 19:603-613

20. Givnish TJ (2002) Ecological constraints on the evolution of plasticity in plants. Evol Ecol 16:213242

21. Grant PR, Grant BR (2002) Unpredictable evolution in a 30-year study of Darwin's finches. Science 296:707-711

22. Hendry AP (2016) Key questions on the role of phenotypic plasticity in eco-evolutionary dynamics. J Hered 107:25-41

23. Hodge A (2004) The plastic plant: root responses to heterogeneous supplies of nutrients. New Phytol $162: 9-24$

24. Huber-Sannwald E, Jackson RB (2001) Heterogeneous soil-resource distribution and plant responsesfrom individual-plant growth to ecosystem functioning. Progress in Botany 62:451-476 
25. Huber H, Chen X, Hendriks M, Keijsers D, Voesenek LACJ, Pierik R, Poorter H, Kroon Hd, Visser EJW (2012) Plasticity as a plastic response: how submergence-induced leaf elongation in Rumex palustris depends on light and nutrient availability in its early life stage. New Phytol 194:572-582

26. Huber $\mathrm{H}$, von Wettberg EJ, Aguilera A, Schmitt J (2011) Testing mechanisms and context dependence of costs of plastic shade avoidance responses in Impatiens capensis (Balsaminaceae). Am J Bot 98:1602-1612

27. Hulme PE (2008) Phenotypic plasticity and plant invasions: is it all Jack? Funct Ecol 22:3-7

28. Lázaro-Nogal A, Matesanz S, Godoy A, Pérez-Trautman F, Gianoli E, Valladares F (2015) Environmental heterogeneity leads to higher plasticity in dry-edge populations of a semi-arid Chilean shrub: insights into climate change responses. J Ecol 103:338-350

29. Levis NA, Pfennig DW (2016) Evaluating 'plasticity-first' evolution in nature: key criteria and empirical approaches. Trends in Ecology Evolution 31:563-574

30. Levis NA, Pfennig DW (2019) Plasticity-led evolution: evaluating the key prediction of frequencydependent adaptation. Proceedings of the Royal Society B 286: 20182754

31. Liefting M, Hoffmann AA, Ellers J (2009) Plasticity versus environmental canalization: population differences in thermal responses along a latitudinal gradient in Drosophila serrata. Evolution 63:1954-1963

32. Metlen KL, Aschehoug ET, Callaway RM (2009) Plant behavioural ecology: dynamic plasticity in secondary metabolites. Plant Cell Environ 32:641-653

33. Miner BG, Sultan SE, Morgan SG, Padilla DK, Relyea RA (2005) Ecological consequences of phenotypic plasticity. Trends in Ecology Evolution 20:685-690

34. Moczek AP, Sultan S, Foster S, Ledón-Rettig C, Dworkin I, Nijhout HF, Abouheif E, Pfennig DW (2011) The role of developmental plasticity in evolutionary innovation. Proceedings of the Royal Society B (Biological Sciences) 278: 2705-2713

35. Morrissey MB, Hadfield JD (2012) Directional selection in temporally replicated studies is remarkably consistent. Evolution: International Journal of Organic Evolution 66:435-442

36. Mou P, Jones RH, Tan Z, Bao Z, Chen H (2013) Morphological and physiological plasticity of plant roots when nutrients are both spatially and temporally heterogeneous. Plant Soil 364:373-384

37. Murren CJ, Auld JR, Callahan H, Ghalambor CK, Handelsman CA, HM A, Kingsolver JG, Maclean HJ, Masel J, Maughan H, Handelsman CA, Heskel MA, Pfennig DW (2015) Constraints on the evolution of phenotypic plasticity: limits and costs of phenotype and plasticity. Heredity 115:293-301

38. Nicotra AB, Atkin OK, Bonser SP, Davidson AM, Finnegan EJ, Poot UMathesius, Purugganan P, Richards MD, Valladares CL, Kleunen F Mv (2010) Plant phenotypic plasticity in a changing climate. Trends Plant Sci 15:684-692

39. Niklaus PA, Baruffol M, He JS, Ma K, Schmid B (2017) Can niche plasticity promote biodiversityproductivity relationships through increased complementarity? Ecology 98:1104-1116 
40. Niu S, Luo Y, Li D, Cao S, Xia J, Li J, Smith MD (2014) Plant growth and mortality under climatic extremes: An overview. Environ Exp Bot 98:13-19

41. Novoplansky A (2009) Meta-plasticity. 94th ESA Annual Convention 2009

42. Novoplansky A, Goldberg DE (2001) Effects of water pulsing on individual performance and competitive hierarchies in plants. J Veg Sci 12:199-208

43. Palacio-López K, Gianoli E (2011) Invasive plants do not display greater phenotypic plasticity than their native or non-invasive counterparts: a meta-analysis. Oikos 120:1393-1401

44. Parolin P, Lucas C, Piedade MTF, Wittmann F (2010) Drought responses of flood-tolerant trees in Amazonian floodplains. Ann Bot 105:129-139

45. Pfennig DW (2016) Ecological evolutionary developmental biology. In: Kliman RM (ed) Encyclopedia of Evolutionary Biology. Academic Press, Oxford

46. Pigliucci M (2001) Phenotypic Plasticity: Beyond Nature and Nurture. Johns Hopkins University Press, Baltimore (MD)

47. Pigliucci M (2005) Evolution of phenotypic plasticity: where are we going now? Trends in Ecology Evolution 20:481-486

48. Poorter H, Niklas KJ, Reich PB, Oleksyn J, Poot P, Mommer L (2012) Biomass allocation to leaves, stems and roots: meta-analyses of interspecific variation and environmental control. New Phytol 193:30-50

49. Relyea RA, Yurewicz KL (2002) Predicting community outcomes from pair-wise interactions: integrating density- and trait-mediated effects. Oecologia 131:569-579

50. Richards CL, Bossdorf O, Muth NZ, Gurevitch J, Pigliucci M (2006) Jack of all trades, master of some? On the role of phenotypic plasticity in plant invasions. Ecol Lett 9:981-993

51. Scheiner SM (2013) The genetics of phenotypic plasticity. XII. Temporal and spatial heterogeneity. Ecology evolution 3:4596-4609

52. Scheiner SM, Berrigan D (1998) The genetics of phenotypic plasticity. VIII. The cost of plasticity in Daphnia pulex. Evolution 52:368-378

53. Schlichting CD (1986) The evolution of phenotypic plasticity in plants. Annu Rev Ecol Syst 17:667693

54. Schmid B, Weiner J (1993) Plastic relationships between reproductive and vegetative mass in Solidago altissima. Evolution 47:61-74

55. Steams SC (1989) The evolutionary significance of phenotypic plasticity. Bioscience 3:436-445

56. Stearns SC, Kaiscr M, Kawecki TJ (1995) The differential genetic and environmental canalization of fitness components in Drosophila melanogaster. Journal of Evolutionary Biolology 8:539-557

57. Sultan SE, Spencer HG (2002) Metapopulation structure favors plasticity over local adaptation. Am Nat 160:271-283

58. Tanou G, Fotopoulos V, Molassiotis A (2012) Priming against environmental challenges and proteomics in plants: update and agricultural perspectives. Front Plant Sci 3:216 
59. Valladares F, Gianoli E, Gómez JM (2007) Ecological limits to plant phenotypic plasticity. New Phytol 176:749-763

60. Valladares F, Sanchez-Gomez D, Zavala MA (2006) Quantitative estimation of phenotypic plasticity: Bridging the gap between the evolutionary concept and its ecological applications. J Ecol 94:11031116

61. Van Buskirk J (2017) Spatially heterogeneous selection in nature favors phenotypic plasticity in anuran larvae. Evolution 71:1670-1685

62. Van Buskirk J, Steiner UK (2009) The fitness costs of developmental canalization and plasticity. Journal of Evolution Biolology 22:852-860

63. van Kleunen M, Fischer M (2005) Constraints on the evolution of adaptive phenotypic plasticity in plants. New Phytol 166:49-60

64. Via S, Lande R (1985) Genotype-environment interaction and the evolution of phenotypic plasticity. Evolution 39:505-522

65. Wagner GP, Booth G, Bagheri-Chaichian H (1997) A population genetic theory of canalization. Evolution 51:329-347

66. Walter J, Jentsch A, Beierkuhnlein C, Kreyling J (2013) Ecological stress memory and cross stress tolerance in plants in the face of climate extremes. Environ Exp Bot 94:3-8

67. Wang S, Callaway RM, Zhou D-W, Weiner J (2017) Experience of inundation or drought alters the responses of plants to subsequent water conditions. J Ecol 105:176-187. doi:10.1111/13652745.12649

68. Weijschedé J, Martínková J, Kroon Hd, Huber H (2006) Shade avoidance in Trifolium repens: costs and benefits of plasticity in petiole length and leaf size. New Phytol 172:655-666

69. Weinig C, Delph IF (2001) Phenotypic plasticity early in life constrains developmental responses later. Evolution 5:930-936

70. Wright AJ, de Kroon H, Visser EJ, Buchmann T, Ebeling A, Eisenhauer N, Weigelt A (2017) Plants are less negatively affected by flooding when growing in species-rich plant communities. New Phytol 213:645-656

\section{Figures}




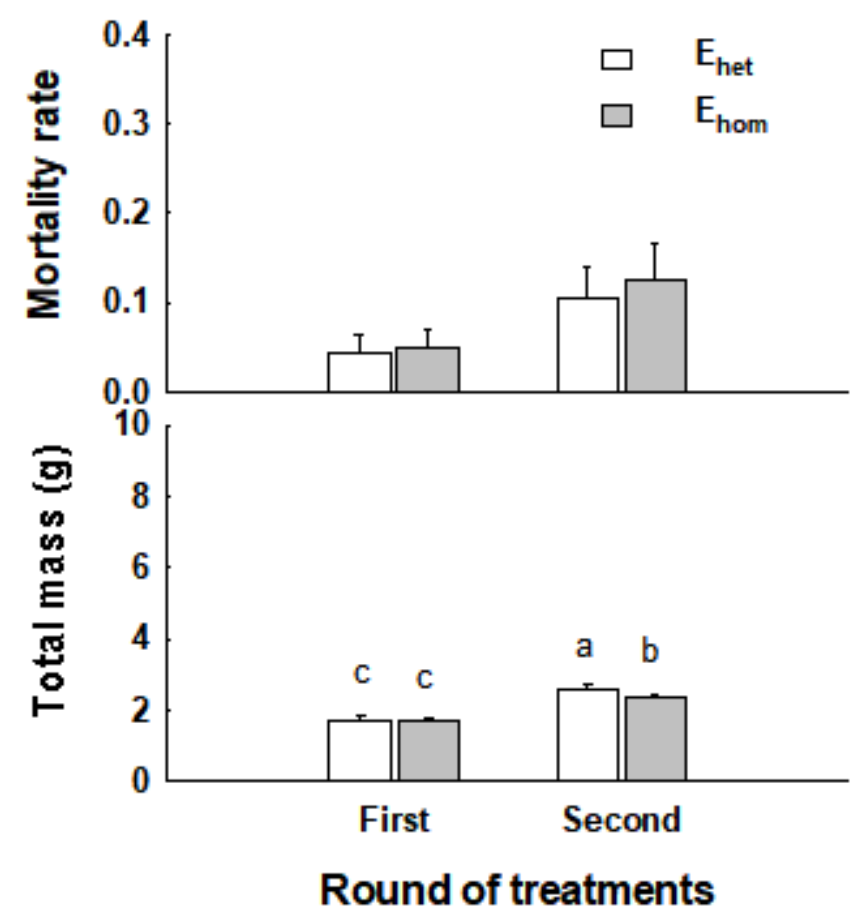

Figure 1

Mean values $( \pm S E)$ of mortality rates and total mass for all species across all late conditions after the $1 \mathrm{st}$ and 2 nd rounds of treatments, showing the effects of the 1 st round of heterogeneous (Ehet) and homogeneous (Ehom) experiences. Different letters denote differences between the two early treatments $(P<0.05)$. 


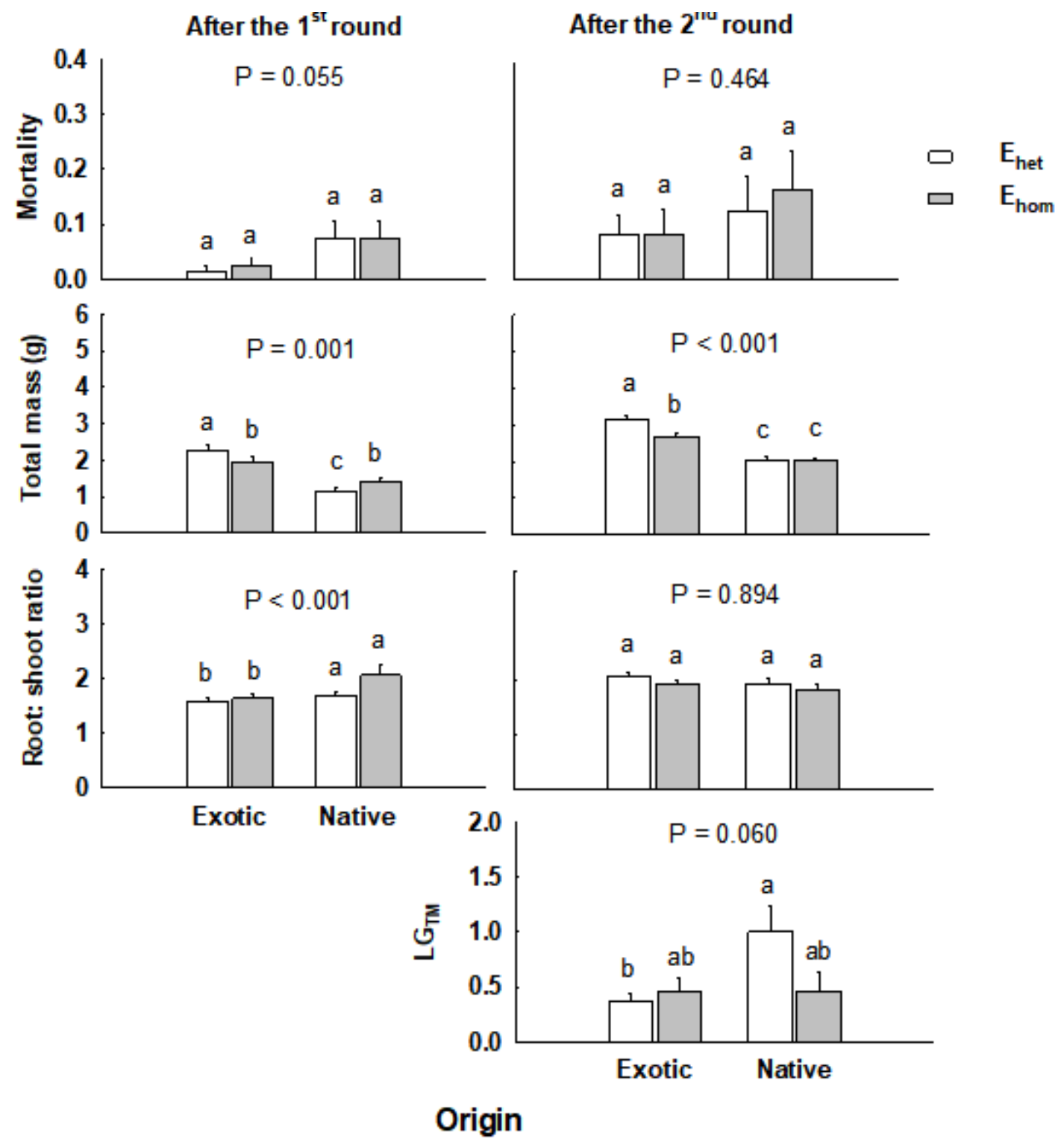

Figure 2

Effects of early heterogeneous (Ehet) and homogeneous (Ehom) treatments on mean values ( \pm SE) of mortality rate, total mass and root:shoot ratio and late growth of total mass (LGTM) for exotic vs. native species after the 1st (left) and 2nd (right) round of treatments. Different lower-case letters denote differences between the early treatments and between exotic and native species; the $\mathrm{P}$ values compare exotic vs. native species across both early treatments. 

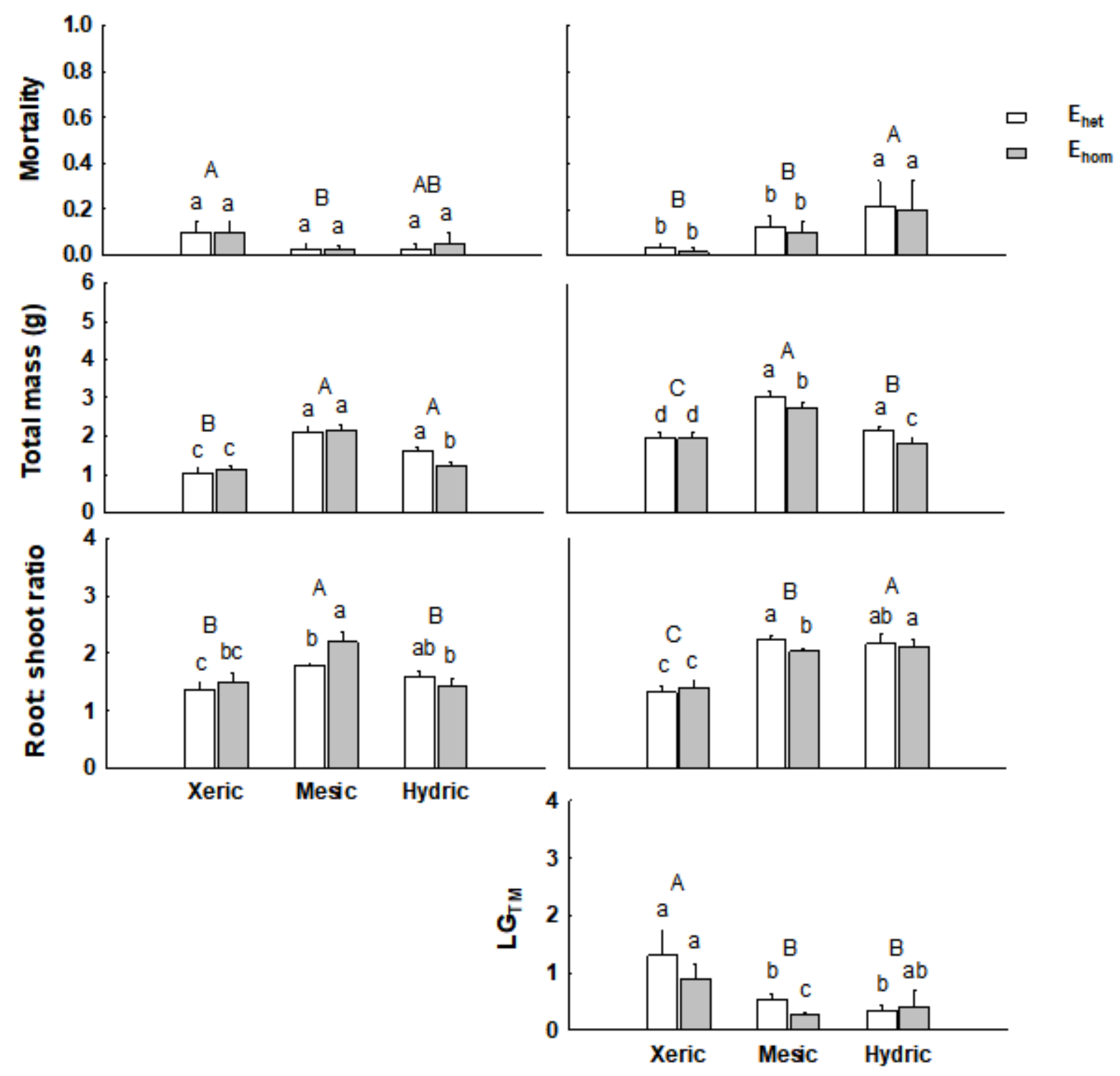

Habitat range

\section{Figure 3}

Effects of early heterogeneous (Ehet) and homogeneous (Ehom) treatments on mean values ( \pm SE) of mortality rate, total mass and root:shoot ratio, and late growth of total mass (LGTM) for species grouped by hydric, mesic and xeric habitat ranges after the $1 \mathrm{st}$ (left) and 2nd (right) round of treatments. Different lower-case letters denote differences between the two early treatments within a group; different uppercase letters denote differences between habitats $(P<0.05)$. 
(a)

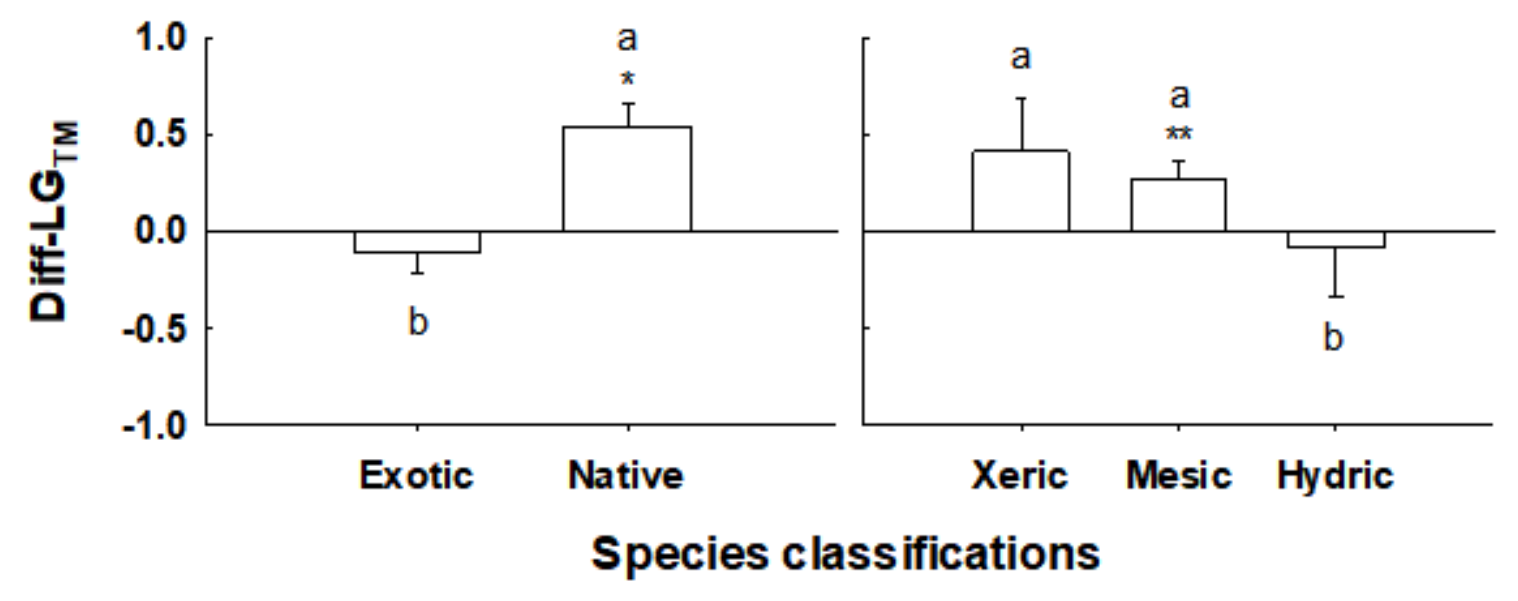

Figure 4

Mean differences in late growth of total mass (LGTM) due to early experience (Diff-LGTM) across all late conditions, for (a) invasive v. native species; (b) species from hydric, mesic and xeric habitat ranges. Significance levels for Diff-LGTM are: ${ }^{*} P<0.10$; $* * P<0.05$, and different letters denote differences among groups of species $(P<0.05)$.

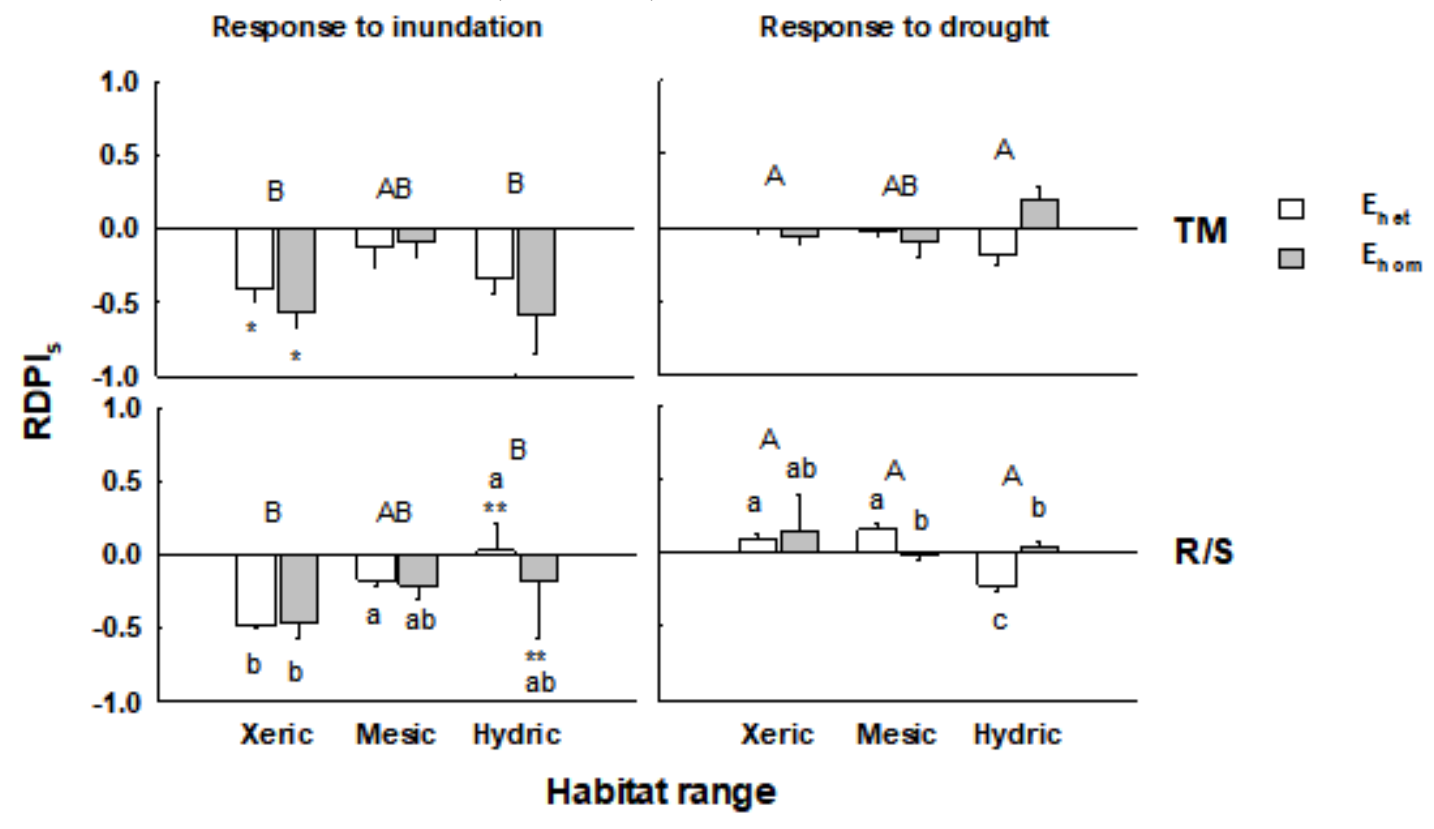

Figure 5

Effects of early heterogeneous (Ehet) and homogeneous (Ehom) treatments on plasticity (RDPIs) in response to late inundation (left) and drought (right) in total mass (TM) and root:shoot ratios (R/S) for species grouped by hydric, mesic and xeric habitat ranges. Significant levels for RDPI values $\left({ }^{*} P<0.05\right.$; ** $P<0.01)$ are reported from the results of ANCOVAs for the effects of the 2 nd round of treatments. Different lower-case letters denote differences between the early treatments within a group of species; 
different upper-case letters denote differences between plasticity to inundation and plasticity to drought as well as between the groups of species $(P<0.05)$.

\section{Supplementary Files}

This is a list of supplementary files associated with this preprint. Click to download.

- Fig.S1.tif

- Fig.S2.tif

- Fig.S3.tif

- Fig.S4.tif

- Fig.S5.tif

- Fig.S6.tif

- Fig.S7.tif

- SMHEP2021.6.17.docx 